\title{
Differentiation of Vibrionaceae Species by Their Cellular Fatty Acid Composition
}

\author{
MARY A. LAMBERT ${ }^{1 *}$ F. W. HICKMAN-BRENNER,${ }^{2}$ J. J. FARMER III, ${ }^{2}$ AND C. WAYNE MOSS ${ }^{1}$
}

Biochemistry Laboratory, Biotechnology Branch, ${ }^{1}$ and Enteric Bacteriology Section, Enteric Diseases Branch, ${ }^{2}$ Division of Bacterial Diseases, Center for Infectious Diseases, Centers for Disease Control, Atlanta, Georgia 30333

\begin{abstract}
The cellular fatty acid compositions of 10 Vibrio species, two Aeromonas species, three Photobacterium species, Plesiomonas shigelloides, and Escherichia coli were determined by using capillary gas-liquid chromatography (GLC). The major fatty acids in all Vibrionaceae species and E. coli were hexadecenoic, hexadecanoic, and octadecenoic acids. Qualitative and quantitative differences in hydroxy, branched, and cyclopropane fatty acids and in isomers of unsaturated 16- and 18-carbon acids were used to divide the 29 strains belonging to 17 species tested into 13 GLC groups. Of the 13 groups, 10 contained one species, 2 contained two species, and 1 contained three species. All of the Vibrionaceae cultures were differentiated from $E$. coli (GLC group I) because the concentration of hexadecenoic acid was greater than the concentration of hexadecanoic acid; in E. coli, this ratio was reversed. Aeromonas hydrophila (GLC group II) and Aeromonas salmonicida (GLC group III) were differentiated from the Vibrio and Photobacterium species and from Plesiomonas shigelloides because the Aeromonas cultures did not contain 3-hydroxylauric acid. Seven of 10 Vibrio species, including Vibrio fluvialis (GLC group IV), Vibrio parahaemolyticus (GLC group V), Vibrio alginolyticus (GLC group V), Vibrio harveyi (GLC group V), Vibrio splendidus (GLC group VI), Vibrio vulnificus (GLC group VII), and Vibrio cholerae (GLC group VIII), contained both cis-9-hexadecenoic and cis-11hexadecenoic acids. These seven species could be differentiated from Vibrio gazogenes (GLC group IX), Vibrio metschnikovii (GLC group XII), Vibrio anguillarum (GLC group XIII), Photobacterium leiognathi (GLC group XIII), Photobacterium phosphoreum (GLC group XI), Photobacterium angustum (GLC group XI), and Plesiomonas shigelloides (GLC group $\mathrm{X}$ ) because these latter seven species did not contain cis-11-hexadecenoic acid. The only Vibrionaceae cultures which contained cyclopropane acids were Photobacterium phosphoreum, Photobacterium angustum, and one of the two strains of Plesiomonas shigelloides examined. Branched-chain acids were found in all species tested, and their concentrations ranged from less than 1 to $22 \%$. Although the 16 Vibrionaceae species tested had many similarities in their cellular fatty acid compositions, there were differences which could be used for differentiation of members of this family at the genus and species levels.
\end{abstract}

The genera assigned to the family Vibrionaceae in Bergey's Manual of Determinative Bacteriology, 8th ed. (31), were Vibrio, Aeromonas, Plesiomonas, Photobacterium, and Lucibacterium. Since the publication of this edition of Bergey's Manual, the nomenclature and classification of the Vibrionaceae have changed because of the new information about the phenotypic and genotypic relationships of the organisms in this family $(1,2,4,9-11,13,14$, 16-18, 21-23, 29, 30). The controversy about the genus Beneckea was resolved when this taxon was abolished and its species were reclassified in the genus Vibrio (3). However, the members of the Vibrionaceae can be difficult to identify because these organisms have a wide range of biochemical, phenotypic, and genetic characteristics.

In recent years, several workers $(5,12,19,20$, 24-28, 34) have used gas-liquid chromatography (GLC) to determine the cellular fatty acid compositions of bacteria and have found that this technique can be helpful in differentiating closely related species. Although there are some reports which describe the lipid composition of Vibrio cholerae $(6,7,15)$ and the fatty acids of several other Vibrio species $(5,28)$ and Aeromonas salmonicida (5), there apparently has not been a comprehensive study of the cellular fatty acids of the family Vibrionaceae. This study was 
done to determine the cellular fatty acid compositions of representative species of the four genera of the Vibrionaceae (Vibrio, Aeromonas, Photobacterium, and Plesiomonas) and to determine whether this information is useful for identifying and classifying the members of this family.

\section{MATERIALS AND METHODS}

Cultures and growth conditions. The cultures which we examined are listed in Table 1. Representative strains from all four genera in the Vibrionaceae were included. The 10 species of Vibrio tested represented most of the major groups in the genus. The strains were from the stock culture collection of the Enteric Bacteriology Section, Centers for Disease Control, Atlanta, Ga., and their identities were confirmed by accepted cultural and biochemical tests and often by deoxyribonucleic acid (DNA)-DNA hybridization (3, $14,29)$. The cultures were given code numbers, and their identities were not known by the workers in the Biochemistry Laboratory until all of the GLC analyses were complete. Cultures were maintained in marine semisolid medium (14) and kept in the dark at ambient temperature. They were transferred to Trypticase soy broth (BBL Microbiology Systems, Cockeysville,
Md.) containing $1 \%$ (final concentration) $\mathrm{NaCl}$ and incubated at $25^{\circ} \mathrm{C}$ for 24 to $48 \mathrm{~h}$. Each broth culture was subcultured in a fresh tube of Trypticase soy broth containing $1 \% \mathrm{NaCl}$ and incubated at $25^{\circ} \mathrm{C}$ for $24 \mathrm{~h}$. This culture was used to inoculate three Trypticase soy agar (BBL) plates (20 by $100 \mathrm{~mm}$ ) which also contained $1 \%$ (final concentration) $\mathrm{NaCl}$. One of these plates was streaked to obtain isolated colonies, and the other two plates were inoculated by spreading $0.3-\mathrm{ml}$ portions of the broth culture over the agar surface. After incubation at $25^{\circ} \mathrm{C}$ for $24 \mathrm{~h}$, the cells on the two plates with confluent growth were removed with sterile distilled water and washed once by centrifugation at $10,000 \times g$. The cells from each culture were divided into approximately equal amounts, placed in screwcapped culture tubes $(20$ by $150 \mathrm{~mm})$, and frozen at $-20^{\circ} \mathrm{C}$. The third plate was examined for purity; an isolated colony was transferred to a tube of Trypticase soy broth containing $1 \% \mathrm{NaCl}$ and incubated for 24 to $48 \mathrm{~h}$. This culture was transferred to marine semisolid medium, to Trypticase soy broth containing $1 \% \mathrm{NaCl}$, and to three plates of Trypticase soy agar containing $1 \% \mathrm{NaCl}$; the cultures were incubated and harvested as described above to obtain cells for the second GLC analysis. Additional plates containing Trypticase soy agar supplemented with $1 \% \mathrm{NaCl}$ were inoculated, incubated, and harvested to obtain cells for the third GLC analysis.

TABLE 1. List of Vibrionaceae and E. coli cultures examined by GLC

\begin{tabular}{|c|c|c|}
\hline Culture & Source $^{a}$ & Comment \\
\hline V. cholerae $9060-79^{\mathrm{T}}$ & ATCC 14035 & Type strain \\
\hline V. cholerae $2507-78$ & V. Baselski strain 401 & Classical-Inaba \\
\hline V. parahaemolyticus $9062-79^{\mathrm{T}}$ & ATCC 17802 & Type strain \\
\hline V. parahaemolyticus $1159-80$ & Stool, Guam & \\
\hline V. alginolyticus $9065-79^{\mathrm{T}}$ & ATCC 17749 & Type strain \\
\hline V. alginolyticus $287-80$ & Stool, Peru & \\
\hline V. vulnificus $9107-79^{\mathrm{T}}$ & ATCC 27562 & Type strain \\
\hline V. vulnificus $9121-79$ & Corneal ulcer & CDC-A1402 \\
\hline V. metschnikovii $9528-78^{\mathrm{T}}$ & NCTC 8443 & Type strain \\
\hline V. metschnikovii $9529-78$ & NCTC 11170 & \\
\hline V. fluvialis $9555-78^{\mathrm{T}}$ & VL 5125 & Type strain \\
\hline V. fluvialis $9554-78$ & VL 2926 & \\
\hline V. anguillarum $9063-79^{\mathrm{T}}$ & ATCC 19264 & Type strain \\
\hline V. harveyi $9098-79^{\mathrm{T}}$ & ATCC 14126 & Type strain \\
\hline V. harveyi $9539-78$ & VL 1493 & \\
\hline V. gazogenes $2820-79^{\mathrm{T}}$ & ATCC 29988 & Type strain \\
\hline V. gazogenes $1289-80$ & Sea water, South Carolina & \\
\hline V. splendidus $9106-79$ & ATCC 25914 & Biotype II \\
\hline A. hydrophila $9079-79^{\mathrm{T}}$ & ATCC 7966 & Type strain \\
\hline A. hydrophila $9080-79$ & ATCC 9071 & \\
\hline A. salmonicida $9087-79$ & ATCC 14174 & Suggested neotype strain \\
\hline A. salmonicida $9542-76$ & Pasteur Institute strain $186-68$ & \\
\hline Plesiomonas shigelloides $9091-79^{\mathrm{T}}$ & ATCC 14029 & Type strain \\
\hline Plesiomonas shigelloides $1261-80$ & Fish tank, Rhode Island & \\
\hline Photobacterium phosphoreum $9540-78$ & NCMB 844 & \\
\hline Photobacterium angustum $9093-79^{\mathrm{T}}$ & ATCC 25915 & Type strain \\
\hline Photobacterium leiognathi $9094-79^{\mathrm{T}}$ & ATCC 25521 & Type strain \\
\hline E. coli $\mathrm{U} 9-41$ & $\mathrm{CDC}$ & 0 group 2, standard strain \\
\hline E. coli $\mathrm{Bi} 7458-41$ & $\mathrm{CDC}$ & 0 group 6 , standard strain \\
\hline
\end{tabular}

${ }^{a}$ ATCC, American Type Culture Collection, Rockville, Md.; NCTC, National Collection of Type Cultures, Central Public Health Laboratory, London, England; VL, Vibrio Laboratory, Maidstone, Kent, England NCMB, National Collection of Marine Bacteria, Torry Research Station, Aberdeen, Scotland; CDC, Centers for Disease Control, Atlanta, Ga. 
Preparation of cellular FAME. To prepare fatty acid methyl esters (FAME), cells were thawed, and $4 \mathrm{ml}$ of a saponification reagent consisting of $5 \% \mathrm{NaOH}$ in $50 \%$ aqueous methanol $(50 \mathrm{~g}$ of $\mathrm{NaOH}, 500 \mathrm{ml}$ of methanol, $500 \mathrm{ml}$ of distilled water) was added. The tube was sealed with a Teflon-lined cap, and the sample was heated in a $100^{\circ} \mathrm{C}$ water bath for $30 \mathrm{~min}$. The sample was cooled to ambient temperature, $5 \mathrm{ml}$ of $15 \% \mathrm{HCl}$-methanol reagent $(150 \mathrm{ml}$ of concentrated $\mathrm{HCl}, 850 \mathrm{ml}$ of methanol) was added, and the mixture was heated for $15 \mathrm{~min}$ at $100^{\circ} \mathrm{C}$. After cooling, $1 \mathrm{ml}$ of a saturated aqueous solution of $\mathrm{NaCl}$ was added, and the FAME were extracted with $10 \mathrm{ml}$ of a mixture of diethyl ether and normal hexane $(1: 1, \mathrm{vol} / \mathrm{vol})$. The extraction step was repeated, and the ether-hexane layers containing the methyl esters were combined in a $100-\mathrm{ml}$ beaker. The FAME sample was evaporated under a gentle stream of nitrogen gas to approximately $0.3 \mathrm{ml}$ and then transferred to a screw-capped test tube (13 by $100 \mathrm{~mm})$. A $0.2-\mathrm{ml}$ portion of ether-hexane was used to rinse the beaker, and this rinse was combined with the contents of the test tube. The methyl ester sample was mixed with $0.5 \mathrm{ml}$ of $0.1 \mathrm{M}$ phosphate buffer ( $14.2 \mathrm{~g}$ of $\mathrm{Na}_{2} \mathrm{HPO}_{4}$ per liter, $4.0 \mathrm{~g}$ of $\mathrm{NaOH}$ per liter). After 5 to $10 \mathrm{~min}$ at ambient temperature, the ether-hexane layer was removed and placed in a clean test tube ( 13 by $100 \mathrm{~mm})$, and the aqueous layer was extracted with 0.3 to $0.4 \mathrm{ml}$ of ether-hexane $(1: 1$, $\mathrm{vol} / \mathrm{vol})$. The two organic phases were combined and concentrated to a volume of 0.3 to $0.4 \mathrm{ml}$. If the organic phase did not completely separate from the aqueous phase, 0.05 to $0.1 \mathrm{ml}$ of methanol was added, and the mixture was centrifuged at $1,000 \times g$ for 3 to 5 min before the organic phase was removed. The FAME samples were stored at $-20^{\circ} \mathrm{C}$ until they were analyzed by GLC.

Acylation of hydroxy FAME. One-third of each FAME sample was transferred to a screw-capped test tube $(13$ by $100 \mathrm{~mm})$, and $0.3 \mathrm{ml}$ of hexane was added. Approximately $0.5 \mathrm{~g}$ of anhydrous $\mathrm{Na}_{2} \mathrm{SO}_{4}$ was mixed with the sample. After centrifugation at $1,000 \times g$ for 3 to $5 \mathrm{~min}$, the hexane was decanted into a clean tube $(13$ by $100 \mathrm{~mm}$ ), and $0.2 \mathrm{ml}$ of trifluoroacetic acid anhydride (Pierce Chemical Co., Rockford, Ill.) was added. The tube was sealed with a Teflon-lined cap, and the contents were heated in an $85^{\circ} \mathrm{C}$ water bath for $5 \mathrm{~min}$. The sample was cooled to ambient temperature, and the trifluoroacetylated methyl esters were evaporated just to dryness with nitrogen gas. The sample was reconstituted to a volume of $0.1 \mathrm{ml}$ with a hexane for analysis by GLC.

Hydrogenation of unsaturated FAME. One-third of each FAME sample was transferred to a $10-\mathrm{ml}$ vacuum hydrolysis tube (Kontes Glass Co., Vineland, N.J.) and gently evaporated to dryness with nitrogen gas. The methyl esters were reconstituted with a mixture of chloroform and methanol $(3: 1, \mathrm{vol} / \mathrm{vol})$ and hydrogenated by a modification of the method of Brian and Gardner (6). The tube was sealed with an evacuation connector (Kontes Glass Co.), and hydrogen gas was added to the sample every $15 \mathrm{~min}$ for 60 to $90 \mathrm{~min}$. The hydrogenated sample was filtered into a clean test tube (13 by $100 \mathrm{~mm})$; the reaction tube, the filter paper, and the catalyst ( $5 \%$ platinum on powdered charcoal) were rinsed three times with small volumes of chloroformmethanol, which were combined with the contents of the tube. The hydrogenated FAME were evaporated with nitrogen gas and reconstituted to a volume of 0.1 $\mathrm{ml}$ with hexane for GLC analysis.

Gas chromatography. The FAME samples were analyzed on a fused silica capillary column $(25 \mathrm{~m}$ by $0.2 \mathrm{~mm}$ [inside diameter]) coated with SE-54 (1\% vinyl, 5\% phenyl, methyl silicone; Hewlett-Packard, Avondale, $\mathrm{Pa}$.). The column was installed in a PerkinElmer model 900 gas chromatograph (Perkin Elmer, Norwalk, Conn.) that had been modified to accept a capillary column. For analysis of the samples, the column was temperature programmed from 130 to $250^{\circ} \mathrm{C}$ at $6.5^{\circ} \mathrm{C} / \mathrm{min}$ and maintained at $250^{\circ} \mathrm{C}$ for $5 \mathrm{~min}$. The instrument was equipped with an all-glass capillary system and flame ionization detector. The injector temperature was $250^{\circ} \mathrm{C}$, and the detector temperature was $270^{\circ} \mathrm{C}$. The carrier gas was helium at a flow rate of approximately $0.8 \mathrm{ml} / \mathrm{min}$; the sample size was $1 \mu \mathrm{l}$, with a split ratio of approximately 50:1.

The FAME peaks were identified by retention time comparisons with authentic methyl ester standards (Supelco, Inc., Bellefonte, Pa.; Applied Science Div., Milton Roy Co., State College, Pa.). Quantitation of the peak areas was done with a Hewlett-Packard model 3390 reporting integrator. The identities of the hydroxy acids and the unsaturated acids in the samples were confirmed after trifluoroacetylation and hydrogenation $(6,25,26)$, respectively. The identities of most acids were also confirmed with a model 21-491B mass spectrometer (DuPont Co., Wilmington, Del.) interfaced with a Varian model 2700 gas chromatograph (Varian, Palo Alto, Calif.) through an all-glass system. The methyl esters were separated on a $3 \%$ OV-101 (methyl silicone) glass column ( $2 \mathrm{~m}$ by $2 \mathrm{~mm}$ [inside diameter]) for mass spectral analysis $(8,26)$. The isomers of the unsaturated 16- and 18-carbon fatty acids (16:1 and 18:1 acids, respectively) were also identified with a Hewlett-Packard model 5880 gas chromatograph, as described previously (34).

\section{RESULTS}

The relative percentages of the cellular fatty acids of the Vibrionaceae species tested and Escherichia coli are shown in Table 2. Each culture was grown and tested three times, and the values in Table 2 are the means from these determinations. The major fatty acids found in all of the cultures were unsaturated 16-carbon (16:1) and 18-carbon (18:1) acids and the saturated 16-carbon acid (16:0 acid). The most abundant isomers of $16: 1$ and 18:1 acids found in all but two of the cultures were cis-9-hexadecenoic acid $\left(\Delta^{9}-16: 1\right.$ acid) and cis-11-octadecenoic acid $\left(\Delta^{11}-18: 1\right.$ acid). Sixteen of the cultures also contained cis-11-hexadecenoic acid $\left(\Delta^{11}-16: 1\right.$ acid) and cis-12-octadecenoic acid $\left(\Delta^{-12}-18: 1\right.$ acid); the concentrations of these two acids ranged from less than $1 \%$ (trace) to $22 \%$. All of the cultures contained small ( 1 to $5 \%$ ) to moderate $(6$ to $14 \%)$ amounts of myristic (14:0) and 3hydroxymyristic (3-OH-14:0) acids and most contained trace to moderate amounts of lauric $(12: 0)$, 3-hydroxylauric $(3-\mathrm{OH}-12: 0)$, iso- 
TABLE 2. Cellular fatty acid compositions of 16 Vibrionaceae species and E. coli

\begin{tabular}{|c|c|c|c|c|c|c|c|c|c|c|c|c|c|}
\hline \multirow{2}{*}{ Culture } & \multicolumn{13}{|c|}{ Straight-chain acids } \\
\hline & $12: 0^{a}$ & $14: 0$ & $15: 0$ & $\begin{array}{c}\text { Un } \\
16: 1\end{array}$ & $\begin{array}{c}\Delta^{9}- \\
16: 1\end{array}$ & $\begin{array}{l}\Delta^{11} \\
16: 1\end{array}$ & $16: 0$ & $17: 1$ & $17: 0$ & $\begin{array}{c}\Delta^{9}- \\
18: 1\end{array}$ & $\begin{array}{l}\Delta^{11} \\
18: 1\end{array}$ & $\begin{array}{l}\Delta^{12} \\
18: 1\end{array}$ & $18: 0$ \\
\hline E. coli U9-41 & $4^{b}$ & $5^{c}$ & 6 & - & 15 & - & 25 & - & 2 & - & 25 & - & + \\
\hline E. coli $\mathrm{Bi} 7458-71$ & 4 & 7 & 2 & - & 13 & - & 25 & - & 1 & - & 28 & - & + \\
\hline A. hydrophila $9079-79^{\mathrm{T}}$ & 5 & 4 & 2 & - & 40 & - & 17 & $2^{d}$ & 1 & - & 14 & - & - \\
\hline A. hydrophila $9080-79$ & 4 & 3 & 1 & - & 36 & - & 13 & 2 & 1 & - & 12 & - & - \\
\hline A. salmonicida $9087-79$ & 4 & 2 & 6 & - & 43 & - & 12 & 10 & 4 & - & 10 & - & + \\
\hline A. salmonicida $9542-76$ & 4 & 2 & 4 & - & 45 & - & 17 & 4 & 2 & - & 10 & - & + \\
\hline V. fluvialis $9555-78^{\mathrm{T}}$ & 3 & 4 & 1 & + & 20 & 18 & 12 & 2 & 2 & - & 13 & 6 & 1 \\
\hline V. fluvialis $9554-78$ & 3 & 4 & 2 & + & 21 & 16 & 13 & 3 & 2 & - & 13 & 5 & + \\
\hline V. parahaemolyticus $9062-79^{\mathrm{T}}$ & 2 & 4 & 2 & - & 25 & 6 & 12 & 4 & 5 & - & 24 & 4 & 1 \\
\hline V. parahaemolyticus $1159-80$ & 3 & 4 & 5 & - & 33 & 6 & 10 & 8 & 3 & - & 14 & 2 & + \\
\hline V. alginolyticus $9065-79^{\mathrm{T}}$ & 2 & 4 & 3 & - & 31 & 7 & 13 & 6 & 3 & - & 17 & 2 & + \\
\hline$V$. alginolyticus $287-80$ & 2 & 4 & 3 & + & 35 & 4 & 14 & 5 & 2 & - & 17 & 1 & + \\
\hline V. harveyi $9098-79^{\mathrm{T}}$ & 4 & 7 & 1 & + & 33 & 6 & 15 & 2 & 2 & - & 13 & 2 & 1 \\
\hline V. harveyi $9539-79$ & 2 & 4 & 2 & - & 28 & 13 & 15 & 2 & 3 & - & 16 & 4 & + \\
\hline V. splendidus $9106-79$ & 5 & 6 & + & - & 42 & 6 & 22 & - & + & - & 11 & - & 1 \\
\hline V. vulnificus $9107-79^{\mathrm{T}}$ & - & 2 & + & 1 & 17 & 22 & 18 & 1 & + & - & 14 & 11 & 1 \\
\hline V. vulnificus $9121-79$ & - & 2 & 1 & 1 & 16 & 21 & 22 & 1 & + & + & 13 & 12 & 1 \\
\hline V. cholerae $9060-79^{\mathrm{T}}$ & - & 5 & + & 1 & 36 & 12 & 16 & 1 & + & 1 & 16 & 2 & 1 \\
\hline V. cholerae $2507-78$ & - & 5 & + & 1 & 30 & 19 & 16 & 1 & + & + & 14 & $\overline{5}$ & 1 \\
\hline V. gazogenes $2820-79^{\mathrm{T}}$ & 6 & 8 & + & + & 37 & - & 22 & + & + & - & 13 & - & 1 \\
\hline V. gazogenes $1289-80$ & 4 & 6 & + & + & 41 & - & 26 & + & + & - & 14 & - & 1 \\
\hline Plesiomonas shigelloides $9091-79^{\mathrm{T}}$ & 4 & 3 & 1 & 2 & 41 & + & 24 & + & 1 & 2 & 12 & + & 2 \\
\hline Plesiomonas shigelloides $1261-80$ & 3 & 2 & + & 2 & 42 & 1 & 28 & + & + & 2 & 9 & + & 1 \\
\hline $\begin{array}{l}\text { Photobacterium phosphoreum } \\
9540-78\end{array}$ & 3 & 3 & + & - & 41 & - & 23 & - & + & + & 11 & - & 2 \\
\hline $\begin{array}{l}\text { Photobacterium angustum } \\
9093-79^{\mathrm{T}}\end{array}$ & 4 & 2 & 1 & - & 46 & - & 18 & + & 1 & - & 15 & - & 1 \\
\hline V. metschnikovii $9528-78^{\mathrm{T}}$ & 5 & 6 & + & + & 36 & + & 17 & + & + & + & 26 & + & 1 \\
\hline V. metschnikovii $9529-78$ & 3 & 4 & + & + & 39 & + & 21 & 1 & 1 & + & 24 & + & 1 \\
\hline V. anguillarum $9063-79^{\mathrm{T}}$ & 4 & 6 & + & + & 43 & + & 21 & 1 & + & - & 15 & - & 1 \\
\hline $\begin{array}{l}\text { Photobacterium leiognathi } \\
9094-79^{\mathrm{T}}\end{array}$ & 5 & 4 & 2 & - & 43 & - & 19 & 2 & 1 & - & 16 & - & 1 \\
\hline
\end{tabular}

${ }^{a}$ The number to the left of the colon indicates the number of carbon atoms; the number to the right indicates the number of double bonds. Un, Unidentified acid; $\Delta^{9}, \Delta^{11}$, and $\Delta^{12}$, cis forms of isomers with the double bond in the 9-10, 11-12, and 12-13 positions; i, iso-branched-chain acid; $2-\mathrm{OH}$ and 3-OH, hydroxyl group at carbon atoms 2 and 3, respectively; cyc, cyclopropane fatty acid.

$b$ The values are the percentages of total acids and are means of at least three determinations. - , Not detected; + , trace $(<1 \%)$ amounts found.

${ }^{c}$ Trace or $1 \%$ amounts of $14: 1$ acid were found in all cultures.

${ }^{d}$ Includes total percentage of both isomers of 17:1 (if present).

branched tridecenoic (i-13:1), pentadecanoic (15:0), heptadecenoic (17:1), and heptadecanoic $(17: 0)$ acids. Trace or small $(1 \%)$ amounts of tridecanoic $(13: 0)$, tetradecenoic $(14: 1)$, pentadecenoic (15:1), and hydroxy acids with 10,11, 13, 15 , and 17 carbon atoms were also found in many of the cultures, but these acids are not listed in Table 2; thus, the total percentage of acids in some strains is less than $100 \%$.

The cultures were divided into eight major groups because of qualitative and quantitative differences in their cellular fatty acids. The species which comprised these groups and the acids which were useful in differentiating them are shown in Table 3. We were able to divide the cultures further into an additional five groups when the ratios of the isomers of the $16: 1$ and 18:1 acids were calculated and the percentages of acids with 13,15 , and 17 carbon atoms and all branched-chain acids (with 13 through 18 carbon atoms) were totaled. These values and the cultures assigned to each group are listed in Table 4. Of the 13 groups, 10 contained one species, 2 contained two species, and 1 contained three species.

After the data shown in Tables 2 through 4 were evaluated, a decision tree (Fig. 1) was constructed; this tree illustrates how the 17 species tested were divided into 13 GLC groups. The $E$. coli cultures were included for reference 
TABLE 2-Continued

\begin{tabular}{|c|c|c|c|c|c|c|c|c|c|c|c|c|c|c|}
\hline \multicolumn{9}{|c|}{ Iso-branched-chain acids } & \multicolumn{4}{|c|}{ Hydroxy acids } & \multicolumn{2}{|c|}{$\begin{array}{l}\text { Cyclopropane } \\
\text { acids }\end{array}$} \\
\hline $\mathrm{i}-13: 1$ & $\mathrm{i}-13: 0$ & $\mathrm{i}-14: 0$ & $\mathrm{i}-15: 1$ & $\mathrm{i}-15: 0$ & $\mathrm{i}-16: 0$ & $\mathrm{i}-17: 1$ & $\mathrm{i}-17: 0$ & $\mathrm{i}-18: 0$ & $\begin{array}{l}2-\mathrm{OH}^{-} \\
12: 0\end{array}$ & $\begin{array}{l}3-\mathrm{OH}- \\
12: 0\end{array}$ & $\begin{array}{l}3-\mathrm{OH}- \\
14: 0\end{array}$ & $\begin{array}{l}3-\mathrm{OH}- \\
\mathrm{i}-15: 0\end{array}$ & $17-\mathrm{cyc}$ & 19-cyc \\
\hline- & - & - & 1 & - & - & - & - & - & - & - & 6 & - & 10 & 1 \\
\hline- & - & - & 2 & - & - & - & - & - & - & - & 6 & - & 11 & 1 \\
\hline- & 1 & - & 1 & 2 & + & 2 & 1 & - & - & - & 4 & 2 & - & - \\
\hline- & 2 & - & 1 & 3 & + & 9 & 7 & - & - & - & 4 & 2 & - & - \\
\hline- & - & - & 1 & - & - & - & - & - & - & - & $\begin{array}{l}4 \\
4\end{array}$ & 1 & - & - \\
\hline- & - & - & 1 & - & - & - & - & - & - & - & 5 & 2 & - & - \\
\hline 1 & 2 & 1 & - & 2 & 3 & + & 3 & 1 & - & 2 & 1 & + & - & - \\
\hline 2 & 2 & 1 & - & 2 & 4 & + & 3 & + & - & 2 & 1 & + & - & - \\
\hline 1 & 2 & - & - & 1 & + & - & 2 & - & - & 2 & 2 & - & - & - \\
\hline 1 & 2 & - & - & 1 & 1 & - & 2 & - & - & 2 & 1 & - & - & - \\
\hline 1 & 1 & + & - & 1 & 2 & - & 2 & - & - & 3 & 2 & - & - & - \\
\hline 1 & 1 & + & - & + & 2 & - & 2 & - & - & 3 & 2 & - & - & - \\
\hline 2 & 1 & 1 & - & - & 2 & - & 1 & + & - & 3 & 3 & - & - & - \\
\hline 1 & 2 & + & - & + & 1 & - & 3 & + & - & 2 & 1 & - & - & - \\
\hline 2 & - & - & - & - & - & - & - & - & - & 3 & 1 & + & - & - \\
\hline 1 & - & + & - & - & 2 & - & - & 1 & + & 4 & 4 & 1 & - & - \\
\hline+ & - & - & - & - & 1 & - & + & + & + & 3 & 4 & 2 & - & - \\
\hline 1 & - & + & - & - & 2 & - & - & + & + & 4 & 1 & - & - & - \\
\hline+ & - & + & - & - & 3 & - & - & 1 & + & 3 & 1 & - & - & - \\
\hline 2 & - & - & - & - & - & - & - & - & 3 & 6 & 2 & - & - & - \\
\hline 1 & - & - & - & - & - & - & - & - & 1 & 5 & 1 & - & - & - \\
\hline 1 & - & - & - & - & - & - & - & - & - & 4 & 2 & - & - & - \\
\hline 1 & - & - & - & - & - & - & - & - & - & 4 & 2 & - & 2 & - \\
\hline 2 & - & - & - & - & - & - & - & - & - & 4 & 1 & - & 10 & - \\
\hline 2 & - & - & - & - & - & - & - & - & - & 4 & 2 & - & 4 & - \\
\hline 2 & - & - & - & - & - & - & - & - & - & 3 & 2 & 2 & - & - \\
\hline 1 & - & - & - & - & 1 & - & - & + & - & 2 & 1 & 1 & - & - \\
\hline 2 & - & + & - & - & 3 & - & - & + & - & 2 & 1 & + & - & - \\
\hline 1 & - & - & - & - & - & - & - & - & - & 4 & 1 & - & - & - \\
\hline
\end{tabular}

purposes since this is the type species of the type genus of the family Enterobacteriaceae. The fatty acid composition of this species has been studied extensively $(5,12,19,20,27)$, and we were able to determine whether the medium used (Trypticase soy agar containing $1 \% \mathrm{NaCl}$ ) significantly altered its fatty acid composition. The $E$. coli cultures were assigned to GLC group

TABLE 3. Differentiation of 16 Vibrionaceae species and $E$. coli into eight major groups by cellular fatty $\operatorname{acids}^{a}$

\begin{tabular}{|c|c|c|c|c|c|c|c|c|}
\hline Group & Species & $\begin{array}{c}16: 1> \\
16: 0\end{array}$ & $\begin{array}{c}\text { 3-OH-12:0 } \\
(\geq 2 \%)\end{array}$ & $\begin{array}{c}\Delta^{11}-16: 1 \\
(\geq 4 \%)\end{array}$ & $\begin{array}{l}12: 0 \\
(\geq 2 \%)\end{array}$ & $\begin{array}{c}2-\mathrm{OH}-12: 0 \\
(\geq 1 \%)\end{array}$ & $\begin{array}{c}\text { Un 16:1, } \\
\Delta^{9}-18: 1 \\
(2 \%)\end{array}$ & $\begin{array}{l}17-\mathrm{cyc} \\
(\geq 3 \%)\end{array}$ \\
\hline 1 & E. coli & - & - & - & + & - & - & + \\
\hline 2 & A. hydrophila, A. salmonicida & + & - & - & + & - & - & - \\
\hline 3 & $\begin{array}{l}\text { V. fuvialis, V. parahaemolyticus, } \\
\text { V. alginolyticus, V. harveyi, } V . \\
\text { splendidus }\end{array}$ & + & + & + & + & - & - & - \\
\hline 4 & V. vulnificus, V. cholerae & + & + & + & - & - & - & - \\
\hline 5 & V. gazogenes & + & + & - & + & + & - & - \\
\hline 6 & Plesiomonas shigelloides & + & + & - & + & - & + & - \\
\hline 7 & $\begin{array}{l}\text { Photobacterium phosphoreum, } \\
\text { Photobacterium angustum }\end{array}$ & + & + & - & + & - & - & + \\
\hline 8 & $\begin{array}{l}\text { V. metschnikovii, V. anguillarum, } \\
\text { Photobacterium leiognathi }\end{array}$ & + & + & - & + & - & - & - \\
\hline
\end{tabular}

\footnotetext{
${ }^{a}$ See text and footnote $a$ of Table 2 for explanations of acid designations.
} 
TABLE 4. Ratios and total percentages of selected fatty acids of 16 Vibrionaceae species and E. coli

\begin{tabular}{|c|c|c|c|c|c|c|c|c|}
\hline \multirow{2}{*}{$\begin{array}{l}\text { GLC } \\
\text { group }\end{array}$} & \multirow{2}{*}{ Culture } & \multicolumn{4}{|c|}{ Ratios } & \multicolumn{2}{|c|}{$\begin{array}{c}\% \text { of } 13-, 15-, \text { and } 17- \\
\text { carbon acids }\end{array}$} & \multirow{2}{*}{$\begin{array}{c}\% \text { of } \\
\text { branched } \\
\text { chain } \\
\text { acids }^{d}\end{array}$} \\
\hline & & $\begin{array}{l}16: 1 / \\
16: 0^{a}\end{array}$ & $\begin{array}{l}\Delta^{9}-16: 1 / \\
\Delta^{11}-16: 1\end{array}$ & $\begin{array}{l}16: 0 / \\
18: 1^{b}\end{array}$ & $\begin{array}{l}\Delta^{11}-18: 1 / \\
\Delta^{12}-18: 1\end{array}$ & $\begin{array}{l}\text { Straight } \\
\text { chain }\end{array}$ & $\begin{array}{l}\text { Iso-branched } \\
\text { chain }\end{array}$ & \\
\hline \multirow[t]{2}{*}{ I } & E. coli $\mathrm{U} 9-41$ & 0.6 & & 1.0 & & 8 & 1 & 1 \\
\hline & E. coli $\mathrm{Bi} 7458-71$ & 0.5 & & 0.9 & & 3 & 2 & 2 \\
\hline \multirow[t]{2}{*}{ II } & A. hydrophila $9079-79^{\mathrm{T}}$ & 2.4 & & 1.1 & & 5 & 7 & 7 \\
\hline & A. hydrophila 9080-79 & 2.9 & & 1.1 & & 4 & 22 & 22 \\
\hline \multirow[t]{2}{*}{ III } & A. salmonicida $9087-79$ & 3.6 & & 1.2 & & 22 & 1 & 1 \\
\hline & A. salmonicida $9542-76$ & 2.7 & & 1.7 & & 12 & 1 & 1 \\
\hline \multirow[t]{2}{*}{ IV } & V. fluvialis $9555-78^{\mathrm{T}}$ & 3.2 & 1.1 & 0.6 & 2.2 & 6 & 8 & 13 \\
\hline & V. fuvialis $9554-78$ & 2.9 & 1.3 & 0.7 & 2.6 & 8 & 9 & 14 \\
\hline \multirow[t]{6}{*}{ V } & V. parahaemolyticus $9062-79^{\mathrm{T}}$ & 2.6 & 4.2 & 0.4 & 6.0 & 12 & 6 & 6 \\
\hline & V. parahaemolyticus $1159-80$ & 3.9 & 5.5 & 0.6 & 7.0 & 17 & 6 & 7 \\
\hline & V. alginolyticus $9065-79^{\mathrm{T}}$ & 2.9 & 4.4 & 0.7 & 8.5 & 12 & 5 & 7 \\
\hline & V. alginolyticus $287-79$ & 2.8 & 8.7 & 0.8 & 17.0 & 11 & 4 & 6 \\
\hline & V. harveyi $9098-79^{\mathrm{T}}$ & 2.6 & 5.5 & 1.0 & 6.5 & 5 & 4 & 7 \\
\hline & V. harveyi $9539-79$ & 2.7 & 2.3 & 0.8 & 4.0 & 7 & 7 & 8 \\
\hline VI & V. splendidus $9106-79$ & 2.2 & 7.0 & 2.0 & & + & 2 & 2 \\
\hline \multirow[t]{2}{*}{ VII } & V. vulnificus $9107-79^{\mathrm{T}}$ & 2.2 & 0.8 & 0.7 & 1.3 & 1 & 1 & 4 \\
\hline & V. vulnificus $9121-79$ & 1.7 & 0.8 & 0.9 & 1.1 & 2 & + & 1 \\
\hline \multirow[t]{2}{*}{ VIII } & V. cholerae $9060-79^{\mathrm{T}}$ & 3.0 & 3.0 & 0.8 & 8.0 & 1 & 1 & 3 \\
\hline & V. cholerae $2507-78$ & 3.0 & 1.5 & 0.8 & 2.8 & 1 & + & 4 \\
\hline \multirow[t]{2}{*}{ IX } & $V \cdot$ gazogenes $2820-79^{\mathrm{T}}$ & 1.7 & & 1.7 & & + & 2 & 2 \\
\hline & V. gazogenes $1289-80$ & 1.6 & & 1.9 & & + & 1 & 1 \\
\hline \multirow[t]{2}{*}{$\mathrm{X}$} & $\begin{array}{l}\text { Plesiomonas shigelloides } \\
9091-79^{\mathrm{T}}\end{array}$ & 1.8 & & 1.7 & & + & 1 & 1 \\
\hline & $\begin{array}{l}\text { Plesiomonas shigelloides } \\
\quad 1261-80\end{array}$ & 1.6 & & 2.6 & & + & 1 & 1 \\
\hline \multirow[t]{2}{*}{ XI } & $\begin{array}{l}\text { Photobacterium phosphoreum } \\
\text { 9540-78 }\end{array}$ & 1.8 & & 2.1 & & + & 2 & 2 \\
\hline & $\begin{array}{l}\text { Photobacterium angustum } \\
9093-79^{\mathrm{T}}\end{array}$ & 1.4 & & 1.3 & & 2 & 2 & 2 \\
\hline \multirow[t]{2}{*}{ XII } & V. metschnikovii $9528-78^{\mathrm{T}}$ & 2.1 & & 0.7 & & + & 2 & 2 \\
\hline & V. metschnikovii $9529-78$ & 1.9 & & 0.9 & & 2 & 1 & 2 \\
\hline \multirow[t]{2}{*}{ XIII } & $V$. anguillarum $9063-79^{\mathrm{T}}$ & 2.1 & & 1.4 & & 1 & 2 & 5 \\
\hline & $\begin{array}{l}\text { Photobacterium leiognathi } \\
9094-79^{\mathrm{T}}\end{array}$ & 2.3 & & 1.2 & & 5 & 1 & 1 \\
\hline
\end{tabular}

${ }^{a}$ See text and Table 2 , footnote $a$, for explanation of acid designations.

${ }^{b}$ Includes total percentages of both isomers of $18: 1$ acid (if present).

$c+$, Trace $(<1 \%)$ amounts found.

${ }^{d}$ Includes total percentages of iso-branched-chain acids with 13 through 18 carbon atoms.

I and were easily distinguished from all of the Vibrionaceae species tested by the ratios of $16: 1$ and 16:0 acids (Tables 2 through 4). In the Vibrionaceae, the concentration of $16: 1$ acid was at least 1.5 times that of 16:0 acid; in $E$. coli, this ratio was less than 1 . The only hydroxy acid found in $E$. coli in amounts greater than $1 \%$ was 3-OH-14:0, and the only branched-chain acid detected was iso-branched pentadecenoic acid (i-15:1 acid). Moderate amounts of a 17-carbon cyclopropane fatty acid (cis-9,10-methylenehexadecanoic acid [17-cyc]) and small amounts of a 19-carbon cyclopropane fatty acid (cis-11,12methyleneoctadecanoic acid [19-cyc]) were also found in the E. coli cultures. This fatty acid composition is consistent with that found previously for $E$. coli $(12,19,20,27)$.
The two species of Aeromonas examined could be differentiated from all of the other Vibrionaceae species because they did not contain 3-OH-12:0 acid or even trace amounts of i13:1 acid (Tables 2 and 3 and Fig. 1). There were some similarities in the fatty acid profiles of Aeromonas hydrophila (Fig. 2A) and A. salmonicida (Fig. 2B), but these species could be differentiated by GLC because of differences in the total percentages of branched-chain acids with 13,15 , and 17 carbon atoms (Table 4). Although both species of Aeromonas contained moderate to high $(>14 \%)$ total concentrations of acids with 13,15 , and 17 carbon atoms, more than $60 \%$ of these acids in A. hydrophila (GLC group II) were branched-chain rather than straightchain acids. In $A$. salmonicida (GLC group III), 


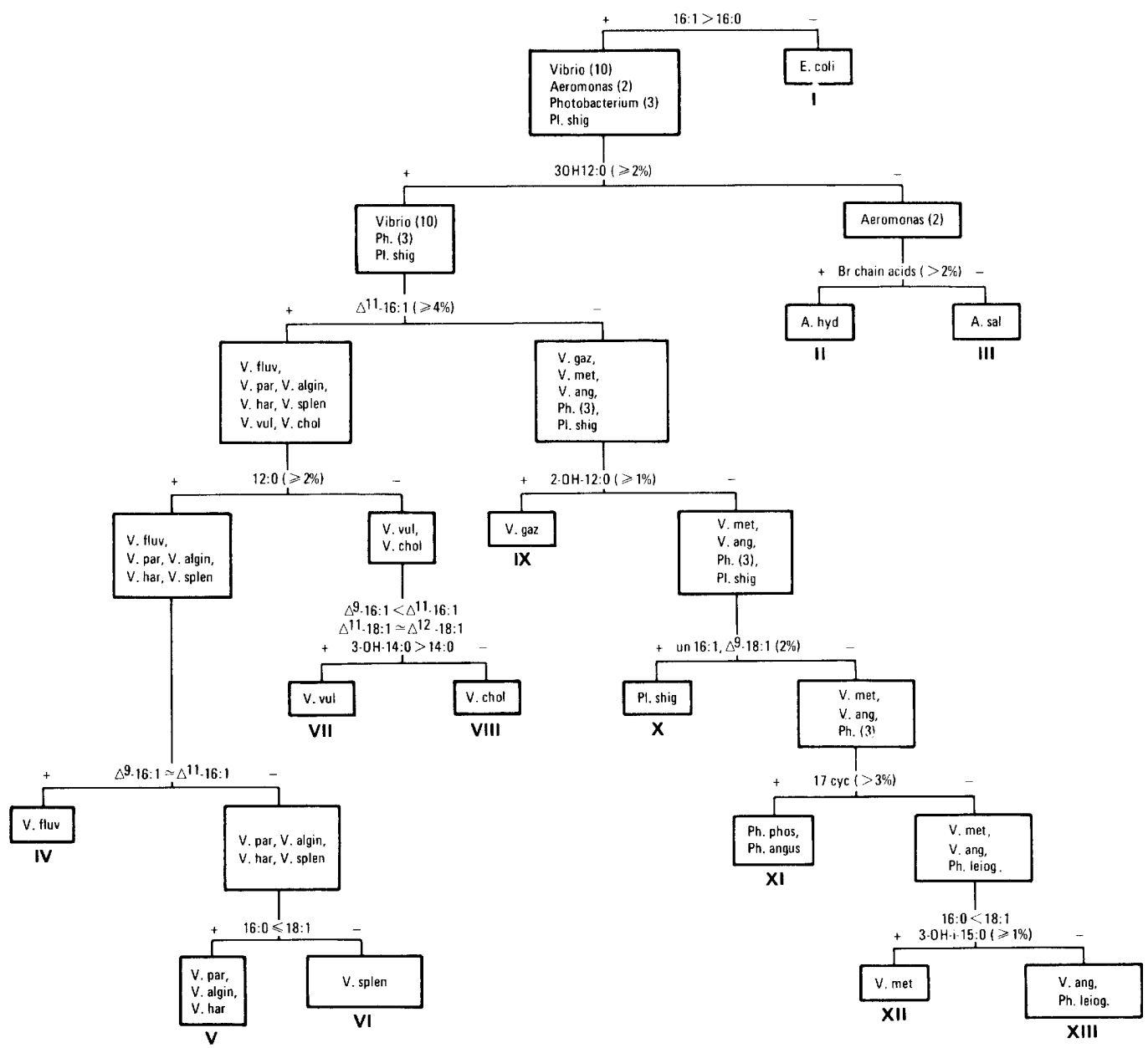

FIG. 1. Decision tree constructed for 16 Vibrionaceae species and $E$. coli based on cellular fatty acid composition. See text and Table 2, footnote $a$, for explanations of acid designations. The numbers in parentheses indicate the numbers of species tested. The roman numerals indicate the GLC groups. Pl. shig, Plesiomonas shigelloides; Ph., Photobacterium; Br chain acids, branched-chain acids; A. hyd, Aeromonas hydrophila; A. sal, Aeromonas salmonicida; V. fluv, Vibrio fuvialis; V. par, Vibrio parahaemolyticus; V. algin, Vibrio alginolyticus; V. har, Vibrio harveyi; V. splen, Vibrio splendidus; V. vul, Vibrio vulnificus; V. chol, Vibrio cholerae; V. gaz, Vibrio gazogenes; V. met, Vibrio metschnikovii; V. ang, Vibrio anguillarum; Ph. phos, Photobacterium phosphoreum; Ph. angus, Photobacterium angustum; Ph. leiog, Photobacterium leiognathi.

more than $90 \%$ of the acids having odd-numbered carbon chains were straight-chain rather than branched-chain acids. Both Aeromonas species contained trace to small amounts of two relatively uncommon hydroxy acids, which were tentatively identified as 3-hydroxy tridecanoic (3-OH-13:0) and 3-hydroxyisopentadecanoic (3-OH-i-15:0) acids. In addition, A. hydrophila contained 2-hydroxypentadecanoic (2-OH-15:0) and 3-hydroxyisoheptanoic (3-OH-i-17:0) acids, and $A$. salmonicida contained 3-hydroxypentadecanoic acid (3-OH-15:0 acid). Some of these acids are not present on the chromatograms shown in Fig. 2 but were observed in chromato- grams of acylated methyl ester samples of these two species.

The presence of $\Delta^{11}-16: 1$ acid allowed us to divide the 10 representative species of Vibrio, the 3 species of Photobacterium, and Plesiomonas shigelloides into two large groups (Tables 2 and 3 and Fig. 1). The first large group included Vibrio fluvialis, Vibrio parahaemolyticus, Vibrio alginolyticus, Vibrio harveyi, Vibrio splendidus, Vibrio vulnificus, and Vibrio cholerae. All of these cultures except $V$. splendidus contained both the $\Delta^{9}$ and $\Delta^{11}$ isomers of $16: 1$ acid and the $\Delta^{11}$ and $\Delta^{12}$ isomers of 18:1 acid. In the second large group, only one major isomer of 

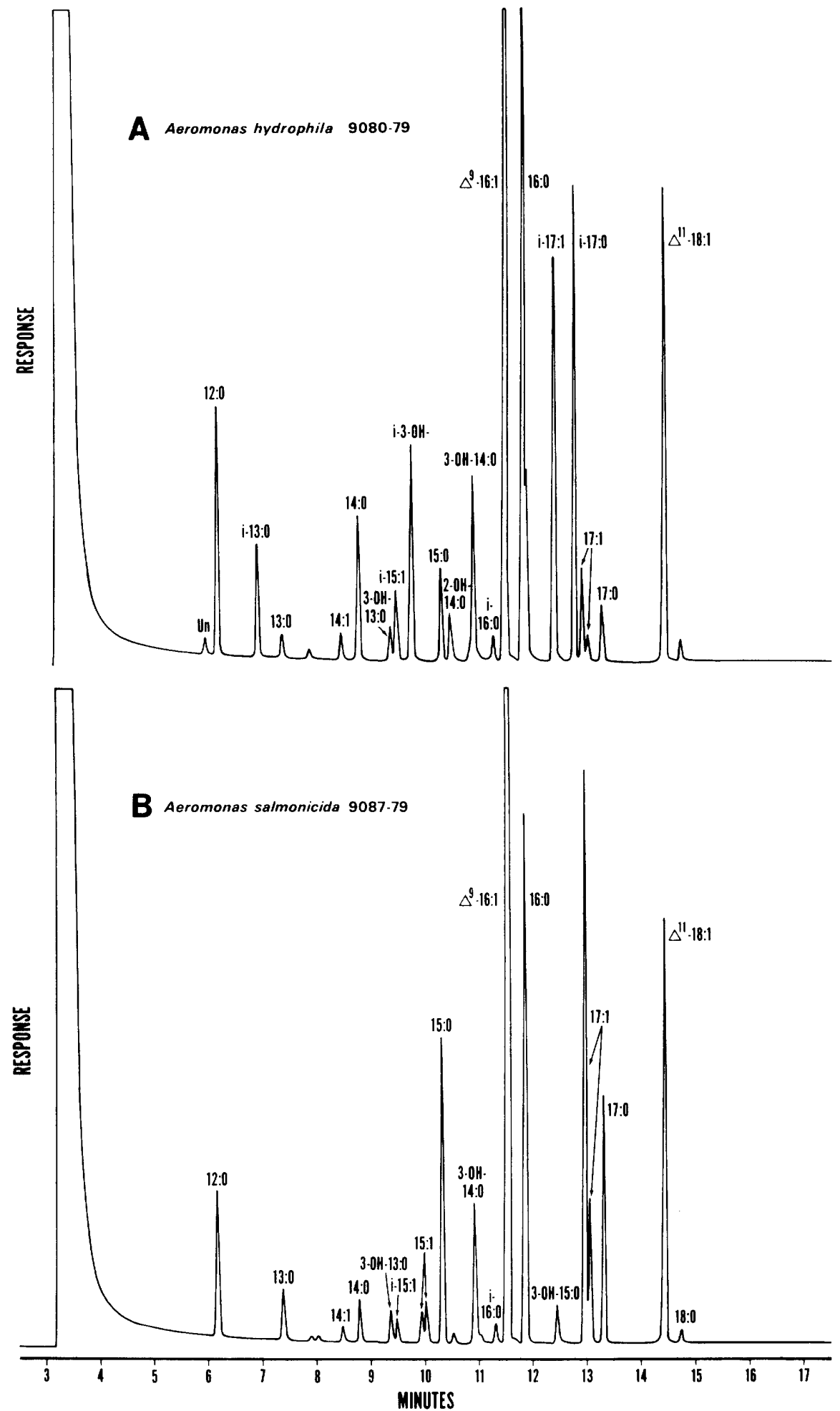

FIG. 2. Gas chromatograms of methylated fatty acids from saponified cells of $A$. hydrophila $9080-79$ (A) and A. salmonicida $9087-79$ (B) analyzed on a 50-m OV-1 fused silica capillary column. See text and Table 2 , footnote $a$, for explanations of acid designations. Note: The peak labeled $\mathrm{i}-3-\mathrm{OH}-\mathrm{in}(\mathrm{A})$ is mislabeled. The correct identity is $\mathrm{i}-15: 0$; the peak on the tailing edge of 16:0 is $\mathrm{i}-3-\mathrm{OH}-15: 0$. 
16:1 acid $\left(\Delta^{9}-16: 1\right)$ and one major isomer of $18: 1$ acid $\left(\Delta^{11}-18: 1\right)$ were found. These cultures included Vibrio gazogenes, Vibrio metschnikovii, Vibrio anguillarum, the three Photobacterium species, and Plesiomonas shigelloides.

In the first large group, which contained $\Delta^{11}$. 16:1 acid, V. fluvialis, V. parahaemolyticus, $V$. alginolyticus, $V$. harveyi, and $V$. splendidus could be differentiated from $V$. vulnificus and $V$. cholerae because the former contained 12:0 acid in concentrations of $2 \%$ or greater; $V$. fluvialis (GLC group IV) was further distinguished from the above four Vibrio species by differences in the ratios of the $16: 1$ acid isomers and by higher total percentages of branched-chain fatty acids (Table 4). As shown in Fig. 3A, $\Delta^{9}-16: 1$ and $\Delta^{11}$. 16:1 acids were present in approximately equal concentrations in $V$. fluvialis. In the other four species however, the concentration of $\Delta^{9}-16: 1$ acid was at least twice that of $\Delta^{11}-16: 1$ (Table 4). A representative chromatogram of one of the cultures, $V$. alginolyticus strain $9065-79^{\mathrm{T}}(\mathrm{T}=$ type strain), is shown in Fig. 3B.

Although there were many similarities in the fatty acids of $V$. parahaemolyticus, $V$. alginolyticus, $V$. harveyi, and $V$. splendidus, these species were subdivided into two GLC groups based on the ratios of the 16:0 and 18:1 acids and on the presence of $\Delta^{12}-18: 1$ acid. In V. parahaemolyticus, $V$. alginolyticus, and $V$. harveyi, the concentration of 16:0 acid was always less than or equal to the total concentration of both $18: 1$ acid isomers (Table 4), and these three species were assigned to GLC Group V. In $V$. splendi$d u s$, the concentration of $16: 0$ acid was twice that of $\Delta^{11}-18: 1$ acid; no $\Delta^{12}-18: 1$ acid was found, and this culture was assigned to GLC group VI. In addition, higher concentrations of acids with 13,15 , and 17 carbon atoms were found in GLC group $\mathrm{V}$ cultures than in $V$. splendidus.

$V$. vulnificus and $V$. cholerae were readily distinguished from GLC group IV, V, and VI cultures (and from all other cultures tested) by the absence of 12:0 acid. Although the fatty acid compositions of these two species were quite similar, we were able to place $V$. vulnificus in GLC group VII and $V$. cholerae in GLC group VIII because of several differences in their fatty acid profiles. In $V$. vulnificus, the concentration of $\Delta^{9}-16: 1$ acid was less than the concentration of $\Delta^{11}-16: 1$ acid, and the concentrations of the two $18: 1$ acid isomers were approximately the same; in the two strains of $V$. cholerae tested, the concentration of $\Delta^{9}-16: 1$ acid was at least 1.5 times greater than the concentration of $\Delta^{11}-16: 1$ acid, and the concentration of $\Delta^{11}-18: 1$ acid was at least 3 times greater than the concentration of $\Delta^{12}-18: 1$ acid (Table 4$)$. In addition, the concentration of 3-OH-14:0 acid in $V$. vulnificus was twice that of 14:0 acid, and in $V$. cholerae the concentration of this hydroxy acid was one-fifth that of 14:0 acid (Table 2). These differences were easily observed when representative chromatograms of $V$. vulnificus (Fig. 4A) and $V$. cholerae (Fig. 4B) were compared. The small amount of 3-OH-i-15:0 acid present in $V$. vulnificus (Table 2) was not observed in Fig. 4 because this acid eluted with 16:0 acid under the GLC conditions used for analysis.

The 10 cultures which were initially included in the second large group because they did not contain the $\Delta^{11}-16: 1$ acid isomer were further divided into five GLC groups because of additional differences in their fatty acid profiles. $V$. gazogenes was assigned to GLC group IX and was differentiated from $V$. metschnikovii, $V$. anguillarum, the three Photobacterium species, and Plesiomonas shigelloides by the presence of 2-hydroxylauric (2-OH-12:0) and 3-OH-12:0 acids (Table 2).

The two strains of Plesiomonas shigelloides contained small amounts of 16:1 and 18:1 acids which eluted just before $\Delta^{9}-16: 1$ and $\Delta^{11}-18: 1$ acids, respectively. These two acids are shown in Fig. $5 \mathrm{~A}$ at retention times of approximately 8.8 and $11.7 \mathrm{~min}$. The retention time of the $18: 1$ acid isomer matched the retention time of a standard of $\Delta^{9}-18: 1$ acid (oleic acid), but the peak at $8.8 \mathrm{~min}$ did not match the retention time of any of the standards available to us. The fatty acid compositions of the two Plesiomonas shigelloides cultures were different from each other because strain 1261-80 contained a small amount of 17-carbon cyclopropane fatty acid and strain $9091-79^{\mathrm{T}}$ did not. Because of this, strain 1261-80 was initially grouped with the two other Vibrionaceae cultures which also contained 17-carbon cyclopropane fatty acid (Photobacterium phosphoreum and Photobacterium angustum). However, the unidentified 16:1 acid, $\Delta^{9}-18: 1$ acid, and 12:0 acid (Tables 2 and 3 and Fig. 5) were found only in the two Plesiomonas shigelloides cultures, and, on this basis, these two cultures were placed in GLC group X.

Photobacterium phosphoreum strain 9540-78 and Photobacterium angustum strain $9093-79^{\mathrm{T}}$ were assigned to GLC group XI and were distinguished from Photobacterium leiognathi, $V$. metschnikovii, and $V$. anguillarum by the presence of 17-carbon cyclopropane fatty acid in concentrations greater than $3 \%$. A representative chromatogram of one of the GLC group XI cultures (Photobacterium phosphoreum strain 9540-78) is shown in Fig. 5B.

The two strains of $V$. metschnikovii were differentiated from $V$. anguillarum and Photobacterium leiognathi by the ratios of the 16:0 and $18: 1$ acids (Table 4). In $V$. metschnikovii (GLC group XII), the concentration of 16:0 acid 


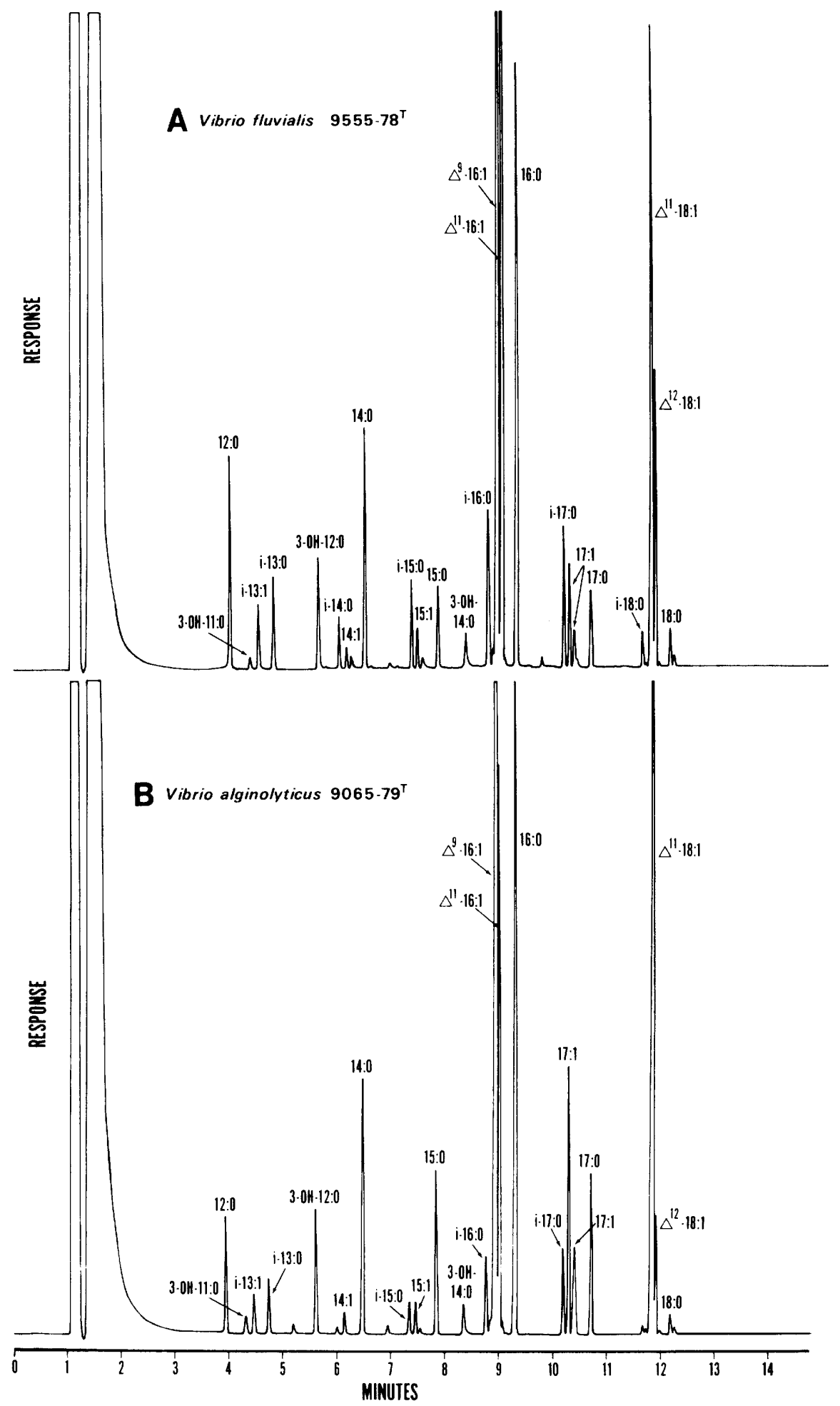

FIG. 3. Gas chromatograms of methylated fatty acids from saponified cells of $V$. fluvialis $9555-78^{\mathrm{T}}$ (A) and $V$. alginolyticus $9065-79^{\mathrm{T}}$ (B) analyzed on a $25-\mathrm{m} \mathrm{SE}-54$ fused silica capillary column. See text and Table 2, footnote $a$ for explanations of acid designations. 


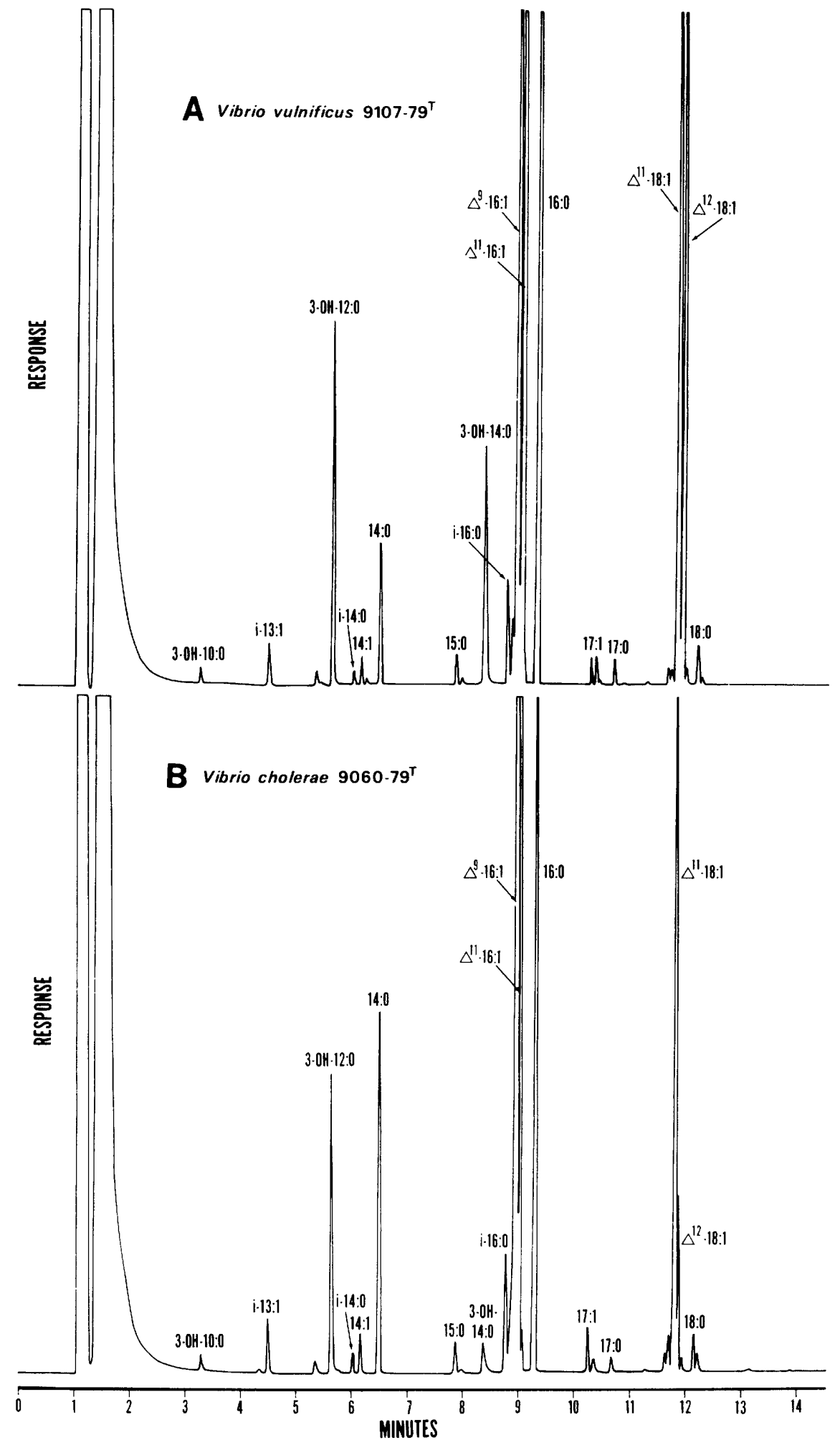

FIG. 4. Gas chromatograms of methylated fatty acids from saponified cells of $V$. vulnificus $9107-79^{\mathrm{T}}$ (A) and $V$. cholerae $9060-79^{\mathrm{T}}$ (B) analyzed on a $25-\mathrm{m} \mathrm{SE}-54$ fused silica capillary column. See text and Table 2, footnote $a$, for explanations of acid designations. 


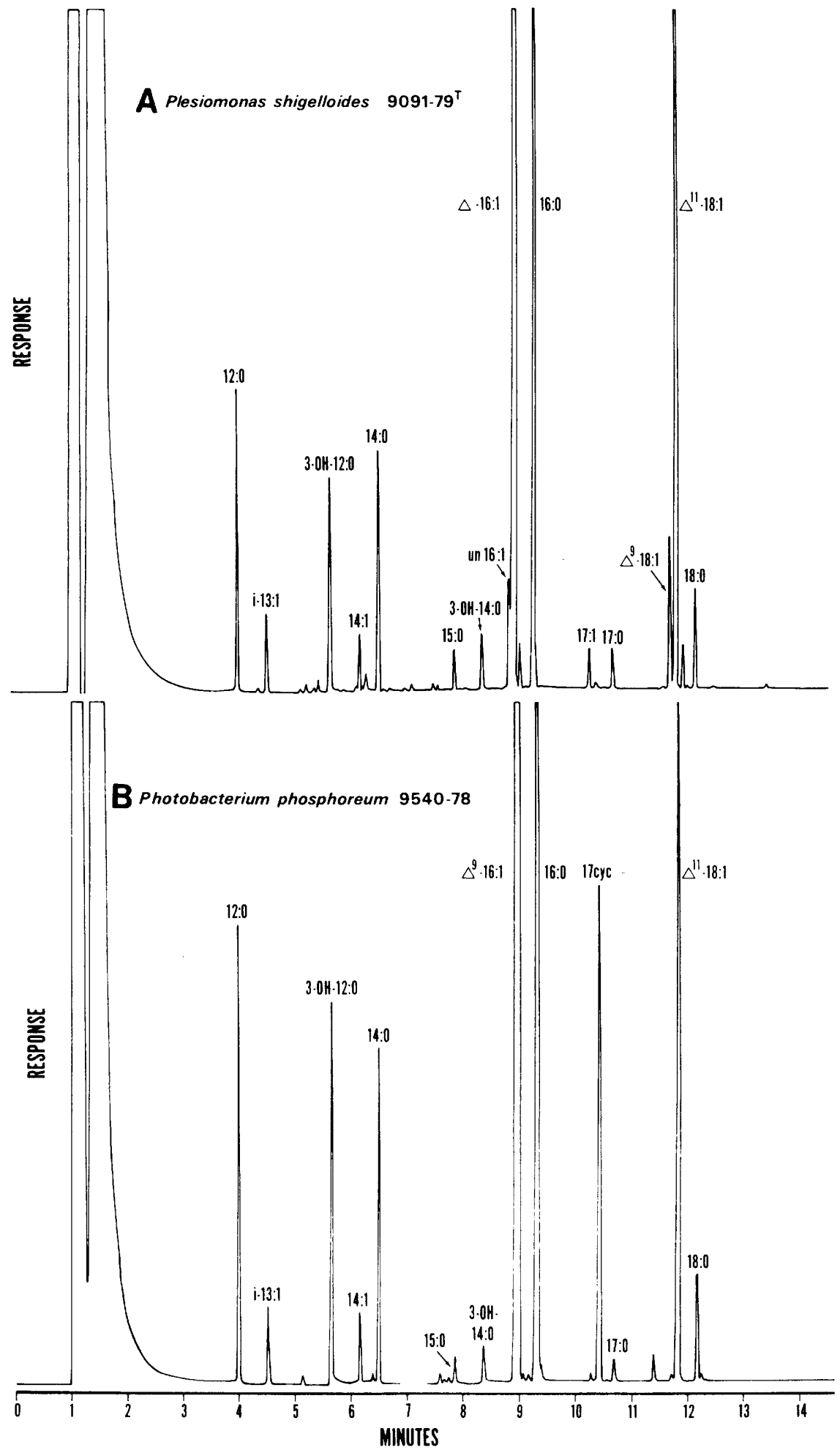

FIG. 5. Gas chromatograms of methylated fatty acids from saponified cells of Plesiomonas shigelloides 9091 $79^{\mathrm{T}}$ (A) and Photobacterium phosphoreum 9540-78 (B) analyzed on a 25-m SE-54 fused silica capillary column. See text and Table 2, footnote $a$, for explanations of acid designations. 
was less than the concentration of $18: 1$ acid; in $V$. anguillarum and Photobacterium leiognathi (GLC group XIII), the concentration of 16:0 acid was greater than the concentration of $18: 1$ acid. In addition, GLC group XII cultures contained small amounts of 3-OH-i-15:0 acid, but this acid was not present in $V$. anguillarum and Photobacterium leiognathi. These two GLC group XIII cultures were somewhat different from each other because $V$. anguillarum contained lower concentrations of straight-chain 13-, 15-, and 17-carbon acids and higher concentrations of branched-chain acids than were found in Photobacterium leiognathi (Table 4). However, we did not subdivide this group.

\section{DISCUSSION}

Our results indicate that cellular fatty acid analysis can be used to help classify and identify many of the members of the Vibrionaceae. By this method the genera Aeromonas and Plesiomonas were shown to be distinct from the other two genera in the family. Two of three species of Photobacterium were also distinct. The fatty acids of the genus Vibrio were heterogenous, and this finding supports the results of other studies which indicate that the species in this genus are not closely related in a phylogenetic sense $(1-4,9,10,21,22,29)$. Fatty acid profiles may be useful in forming a definition for the family Vibrionaceae and in differentiating this family from closely related families, such as the Enterobacteriaceae. Although several of the distinguishing characteristics were not major and were based on the presence or absence of only one acid, the concentration of each acid was reproducible within 5 to $10 \%$ when the cultures were regrown and the GLC analysis was repeated. Although there were strain-to-strain differences in the amounts of some of the acids (Tables 2 and 4), the strains of each species were grouped together. However, additional strains of each species should be examined to expand and confirm the data obtained in this study.

The identities of some of the branched-chain and hydroxy acids are tentative because standards were not available for comparison or because the acids were present in insufficient concentrations for confirmation by mass spectrometry. However, the majority of the peaks were identified on fused silica capillary columns after carefully comparing the FAME chromatograms with standard chromatograms and with the chromatograms obtained after trifluoroacetylation and hydrogenation.

Many of the fatty acids present in the Vibrionaceae cultures are the same as those reported previously for these species $(5-7,15,20,28)$ and found in other gram-negative rod-shaped bacteria, such as members of the Enterobacteriaceae
$(5,19,20,24,27)$. However, we found quantitative and some qualitative differences in the cellular fatty acids of the Vibrionaceae and a representative species of the Enterobacteriaceae, which can be used to differentiate them. In all of the Vibrionaceae species tested by GLC, isomers of $16: 1$ acid $\left(\Delta^{9}-16: 1\right.$ and $\left.\Delta^{11}-16: 1\right)$ were the major fatty acids found, and the concentrations of these acids were at least 1.5 times the concentration of 16:0 acid; in $E$. coli, the ratio of 16:1 acid to 16:0 acid was approximately 0.5 . This difference in the ratios of the $16: 1$ and 16:0 acids in the families Vibrionaceae and Enterobacteriaceae has been observed previously $(5,24$, 28).

Another difference in cellular fatty acid composition between these two families was the absence of cyclopropane fatty acids in most Vibrionaceae species (Tables 2 and 3). These acids are found in all species of Enterobacteriaceae except Proteus vulgaris (20), but they were found only in Photobacterium phosphoreum, Photobacterium angustum, and one of the two strains of Plesiomonas shigelloides examined in this study. Although the cellular fatty acids of additional strains of the Photobacterium species need to be determined, the presence of the 17-carbon cyclopropane fatty acid may serve as a rapid means of distinguishing these two species from the other species of Photobacterium and from other genera in the family Vibrionaceae. In addition, cellular fatty acid analysis may be useful in clarifying the taxonomy of Photobacterium because many of the accepted biochemical tests give inconsistent results and are not very helpful in identifying the species of this genus (2). The type strain of Plesiomonas shigelloides (strain $9091-79^{\mathrm{T}}$ ) did not contain the 17-carbon cyclopropane fatty acid, and additional testing should be done to determine whether this acid is absent in other strains or if its presence is dependent on other factors such as growth temperature or the physiological age of the cells $(12,19,20,27,28)$.

Oliver and Colwell (28) reported that 16:1 acid is the predominant acid and that branched-chain acids are present in the six Vibrio species which they tested. We confirmed these results and found that both unsaturated and saturated isobranched-chain acids were present and that their concentrations differed from species to species. The highest concentrations of branched-chain acids were found in A. hydrophila, V. fluvialis, $V$. parahaemolyticus, $V$. alginolyticus, $V$. harveyi, and $V$. anguillarum. The lowest concentrations were found in A. salmonicida, $V$. splendidus, V. vulnificus (strain 9121-79 $), \quad V$. gazogenes, V. metschnikovii, Plesiomonas shigelloides, and three species of Photobacterium (Table 4). 
These results did not agree with those of Bøe and Gjerde (5), who reported that small to moderate amounts of a 17-carbon cyclopropane fatty acid and anteiso-branched-chain 15- and 17-carbon acids are found in A. salmonicida, $V$. anguillarium, and $V$. parahaemolyticus. These authors also reported higher concentrations of 16- and 18-carbon branched acids than we found for strains of these species. Although we detected small amounts of branched 13-, 15-, and 17carbon acids in $V$. anguillarum and $V$. parahaemolyticus, they were iso-branched-chain acids rather than anteiso-branched acids. A. salmonicida did not contain more than trace or $1 \%$ amounts of branched-chain acids; however, this species did contain small to moderate amounts of unsaturated acids with 15 and 17 carbon atoms (Table 2 and Fig. 2). Cyclopropane fatty acids were not detected in any of these three species (Tables 2 and 3 ).

Although capillary columns have excellent separating characteristics, we have found that samples with complex fatty acid profiles, like most of the Vibrionaceae, still need to be acylated and hydrogenated so that some acids may be correctly identified. For example, our results from capillary GLC on both SE-54 and OV-1 columns and GLC-mass spectrometry showed that an isomer of 15:1 acid eluted at the same retention time as anteiso-pentadecanoic acid, that isomers of 17:1 acid eluted at the same retention times as anteiso-heptadecanoic acid and 17-carbon cyclopropane fatty acids, and that iso-heptadecenoic acid (i-17:1 acid [Fig. 2A]) eluted at the same retention time as 3-hydroxypentadecanoic acid (3-OH-15:0 acid [Fig. 2B]). Thus, it was necessary to hydrogenate $(6,25,26)$ these samples in order to detect and confirm unsaturated, saturated, and cyclopropane fatty acids. Acylation was also required in order to detect and confirm the presence of hydroxy acids in the samples $(25,26,34)$. This information, along with the information from retention time comparisons, helped us correctly interpret the mass spectra of iso- and anteiso-branchedchain acids and unsaturated and cyclopropane fatty acids when standards of some of these acids were not available $(8,25,26)$.

B $\varnothing \mathrm{e}$ and Gjerde (5) did not report that their samples were hydrogenated, and it is possible that unsaturated 15- and 17-carbon acids eluted with or were misidentified as the anteiso and cyclopropane fatty acids. However, these qualitative differences, as well as quantitative differences seen in the 16- and 18-carbon branchedchain acids, could also be due to strain differences, growth conditions, or medium effects $(12,19,20)$.

Our results showed there were several similarities in the fatty acid profiles of $A$. hydrophila (GLC group II) and V. fluvialis (GLC group IV) because both species contained moderate to high total concentrations of straight- and branched-chain 13-, 15-, and 17-carbon fatty acids (Table 4). It is interesting that $V$. fluvialis is different biochemically from other clinically significant Vibrio species and can be confused with Aeromonas $(17,18,22)$. However, the fatty acid composition of $V$. fluvialis was different from that of $A$. hydrophila because 3-OH-12:0 acid and the two isomers of $16: 1$ and 18:1 acids were present and i-17:1 acid was absent (Tables 2 and 3). It appears that analysis of cellular fatty acids by GLC is another technique for differentiating $V$. fluvialis from $A$. hydrophila.

$V$. parahaemolyticus and $V$. alginolyticus are similar biochemically $(2,3,16,33)$ and previously were considered biotypes of the same species (31); however, a numerical analysis of many nutritional and physiological characteristics (4) and DNA-DNA hybridization (29) have shown that these organisms are two distinct species. $V$. parahaemolyticus and $V$. alginolyticus had almost identical fatty acid profiles, and they could not be differentiated. The other species included in GLC group $\mathrm{V}, V$. harveyi, was formerly classified in the genus Lucibacterium, but it was transferred to Vibrio because it is very closely related genetically to $V$. parahaemolyticus and $V$. alginolyticus $(2,3,29)$. These three species also appear to be related chemically since they have similar cellular fatty acid profiles. Although there were minor differences in the cellular fatty acids in this GLC group (GLC group V), these differences were not large enough or consistent enough to divide the organisms further.

The cellular fatty acids of $V$. splendidus (GLC group VI) were quite similar to those of Photobacterium leiognathi, one of the species placed in GLC group XIII. These two species would have been grouped together if Photobacterium leiognathi had contained the $\Delta^{11}-16: 1$ acid isomer (Table 2). Since these two species both have luminous strains and share some of the same biochemical characteristics (1-3), it is not surprising that they have similar fatty acid compositions.

At one time the description of $V$. anguillarum, the other species included in GLC group XIII, was inadequate, and two biotypes of this species were described $(2,3,29)$. Recently, Schiewe et al. (30) proposed that strains which were previously designated $V$. anguillarum biotype 2 be named Vibrio ordalii sp. nov. Since there are several differences in the cultural, biochemical, and DNA sequence relatedness properties between this new species and $V$. anguillarum (biotype 1), testing of well-documented strains of both $V$. ordalii sp. nov. and V. anguillarum by GLC may be useful in differentiating these two species.

Experiments at the Centers for Disease Con- 
trol and other laboratories $(3,21)$ have shown that both $V$. gazogenes (GLC group IX) and $V$. metschnikovii (GLC group XII) have unusual biochemical reactions for Vibrio species because they are oxidase negative and nitrate negative. However, the fatty acid compositions of $V$. gazogenes and $V$. metschnikovii were definitely like those of the other Vibrio species examined because 3-OH-12:0 acid was present and the concentration of $16: 1$ acid was almost twice that of 16:0 acid. Although the fatty acid profiles of $V$. gazogenes and $V$. metschnikovii were similar in some respects, they could be differentiated from each other because of differences in the ratio of 16:0 acid to 18:1 acid and in the hydroxy acids (Tables 2 through 4 ).

In summary, the 16 species of the Vibrionaceae tested could be divided into 12 GLC groups based on the presence or absence of certain hydroxy, branched-chain, cyclopropane, and unsaturated fatty acids. The ratios of some of the acids or their isomers were also useful in dividing the cultures into groups. The influence of growth temperature, medium composition, length of incubation, physiological age of cells, and $\mathrm{Na}^{+}$concentration on the stability of the fatty acid ratios and on the presence of the acids used in differentiating these cultures need to be determined. One problem encountered in studies of such a biochemically diverse group as the Vibrionaceae is that the media and growth conditions used may not be optimal for all species tested. Thus, the fatty acid compositions found may not be truly representative of the species and may change when other media or cultural conditions are used. All of these factors need to be considered in further studies of these bacteria. Additional strains of the species listed in Table 1 and all other Vibrio species need to be tested by GLC to expand the results reported here. Analysis of cellular fatty acids by GLC offers a rapid and alternate method for classifying and identifying the species in the family Vibrionaceae and could be used as a valuable adjunct to classical laboratory techniques.

\section{ACKNOWLEDGMENTS}

The excellent technical assistance of Barbara Kell and the helpful suggestions of Gordon O. Guerrant are gratefully appreciated.

\section{LITERATURE CITED}

1. Baumann, L., S. S. Bang, and P. Baumann. 1980. Study of relationship among species of Vibrio, Photobacterium, and terrestial Enterobacteriaceae by an immunological comparison of glutamine synthetase and superoxide dismutase. Curr. Microbiol. 4:133-138.

2. Baumann, P., and L. Baumann. 1977. Biology of the marine Enterobacteriaceae: genera Beneckea and Photobacterium. Annu. Rev. Microbiol. 31:39-61.

3. Baumann, P., L. Baumann, S. S. Bang, and M. J. Woolkalis. 1980. Reevaluation of the taxonomy of Vibrio, Beneckea, and Photobacterium: abolition of the genus Beneckea. Curr. Microbiol. 4:127-132.
4. Baumann, P., L. Baumann, and J. L. Reichelt. 1973. Taxonomy of marine bacteria: Beneckea parahaemolytica and Beneckea alginolytica. J. Bacteriol. 113:1144-1155.

5. Bøe, B., and J. Gjerde. 1980 . Fatty acid patterns in the classification of some representatives of the families $E_{n}$ terobacteriaceae and Vibrionaceae. J. Gen. Microbiol. 116:41-49.

6. Brian, B. L., and E. W. Gardner. 1968. Fatty acids from Vibrio cholerae lipids. J. Infect. Dis. 118:47-53.

7. Broady, K. W., E. T. Rietschel, and O. Luderitz. 1981. The chemical structure of the lipid A component of lipopolysaccharides from Vibrio cholerae. Eur. J. Biochem. 115:463-468.

8. Campbell, I. M., and J. Naworal. 1969. Mass spectral discrimination between monoenoic and cyclopropanoid, and between normal, iso, and anteiso fatty acid methyl esters. J. Lipid Res. 10:589-592.

9. Citarella, R. V., and R. R. Colwell. 1970. Polyphasic taxonomy of the genus Vibrio: polynucleotide sequence relationships among selected Vibrio species. J. Bacteriol. 104:434-442.

10. Colwell, R. R. 1970. Polyphasic taxonomy of the genus Vibrio: numerical taxonomy of Vibrio cholerae, Vibrio parahaemolyticus, and related Vibrio species. J. Bacteriol. 104:410-433.

11. Davis, B. R., G. R. Fanning, J. M. Madden, A. G. Stejgerwalt, H. B. Bradford, Jr., H. L. Smith, Jr., and D. J. Brenner. 1981. Characterization of biochemically atypical Vibrio cholerae strains and designation of a new pathogenic species, Vibrio mimicus. J. Clin. Microbiol. 14:631639.

12. Goldfine, H. 1972. Comparative aspects of bacterial lipids Adv. Microb. Physiol. 8:2, 3, 22-27, 42.

13. Harwood, C. S. 1978. Beneckea gazogenes sp. nov., a red, facultatively anaerobic, marine bacterium. Curr. Microbiol. 1:233-238.

14. Hickman, F. W., J. J. Farmer III, D. G. Hollis, G. R. Fanning, A. G. Steigerwalt, R. E. Weaver, and D. J. Brenner. 1982. Identification of Vibrio hollisae sp. nov. from patients with diarrhea. J. Clin. Microbiol. 15:395-401.

15. Hisatsune, K., S. Kondo, T. Kawata, and Y. Kishimoto. 1979. Fatty acid composition of lipopolysaccharide of Vibrio cholerae 35A3 (Inaba), NIH 90 (Ogawa), and 4715 (NAG). J. Bacteriol. 138:288-290.

16. Hollis, D. G., R. E. Weaver, C. N. Baker, and C. Thornsberry. 1976. Halophilic Vibrio species isolated from blood cultures. J. Clin. Microbiol. 3:425-431.

17. Huq, M. I., A. K. M. J. Alam, D. J. Brenner, and G. K. Morris. 1980. Isolation of Vibrio-like group, EF-6, from patients with diarrhea. J. Clin. Microbiol. 11:621-624.

18. Kaper, J. B., H. Lackman, R. R. Colwell, and S. W. Joseph. 1981. Aeromonas hydrophila: ecology and toxigenicity of isolates from an estuary. J. Appl. Bacteriol. 50:359-377.

19. Kates, M. 1964. Bacterial lipids. Adv. Lipid Res. 2:17-90.

20. Lechevalier, M. P. 1982 . Lipids in bacterial taxonomy, p 444-445, 495-507, 512, 516. In A. I. Laskin and H. A. Lechevalier (ed.), CRC handbook of microbiology, 2nd ed., vol 4. CRC Press, Inc., Boca Raton, Fla.

21. Lee, J. V., T. J. Donovan, and A. L. Furniss. 1978. Characterization, taxonomy, and emended description of $\mathrm{Vib}$ rio metschnikovii. Int. J. Syst. Bacteriol. 28:99-111.

22. Lee, J. V., P. Shread, A. L. Furniss, and T. N. Bryant. 1981. Taxonomy and description of Vibrio fluvialis, $\mathbf{s p}$. nov. (synonym group $\mathrm{F}$ vibrios, group EF-6). J. Appl. Bacteriol. 50:73-95.

23. Love, M., D. Teebken-Fisher, J. E. Hose, J. J. Farmer III, F. W. Hickman, and G. R. Fanning. 1981. Vibrio damsela, a marine bacterium, causes skin ulcers on the damselfish Chromis punctipinnis. Science 214:1139-1140.

24. Machtiger, N. A., and W. M. O'Leary. 1973. Fatty acid compositions of paracolons: Arizona, Citrobacter, and Providencia. J. Bacteriol. 114:80-85.

25. Moss, C. W. 1978 . New methodology for identification of nonfermentors: gas-liquid chromatographic chemotaxonomy, p. 188-195. In G. L. Gilardi (ed.), Glucose nonfer- 
menting gram-negative bacteria in clinical microbiology. CRC Press, Inc., West Palm Beach, Fla.

26. Moss, C. W., and S. B. Dees. 1975. Identification of microorganisms by gas chromatographic-mass spectrometric analysis of cellular fatty acids. J. Chromatogr. 112:595-604.

27. O'Leary, W. M. 1982. Lipoidal contents of specific microorganisms, p. 393-398. In A. I. Laskin and H. A. Lechevalier (ed.), CRC handbook of microbiology, 2nd ed, vol 4. CRC Press, Inc., Boca Raton, Fla.

28. Oliver, J. D., and R. R. Colwell. 1973. Extractable lipids of gram-negative marine bacteria: fatty acid composition. Int. J. Syst. Bacteriol. 23:442-458.

29. Reichelt, J. L., P. Baumann, and L. Baumann. 1976. Study of the genetic relationships among marine species of the genera Beneckea and Photobacterium by means of in vitro DNA/DNA hybridization. Arch. Mikrobiol. 110:110-120.

30. Schiewe, M. H., T. J. Trust, and J. H. Crosa. 1981. Vibrio ordalii sp. nov.: a causative agent of vibriosis in fish.
Curr. Microbiol. 6:343-348.

31. Shewan, J. M., and M. Veron. 1974. Family II. Vibrionaceae Veron 1965,5245 , p. 340-352. In R. E. Buchanan and N. E. Gibbons (ed.), Bergey's manual of determinative bacteriology, 8 th ed. The Williams \& Wilkins Co., Baltimore.

32. von Graevenitz, A. 1980 . Aeromonas and Plesiomonas, p. 220-225. In E. H. Lennette, A. Balows, W. J. Hausler, and J. P. Truant (ed.), Manual of clinical microbiology, 3rd ed. American Society for Microbiology, Washington, D.C.

33. Wachsmuth, I. K., G. K. Morris, and J. C. Feeley. 1980 Vibrio, p. 226-234. In E. H. Lennette, A. Balows, W. J. Hausler, and J. P. Truant (ed.), Manual of clinical microbiology, 3rd ed. American Society for Microbiology, Washington, D.C

34. Yabuuchi, E., and C. W. Moss. 1982. Cellular fatty acid composition of strains of three species of Sphingobacterium gen. nov. and Cytophaga johnsonae. FEMS Microbiol. Lett. 13:87-91. 